\title{
Research on the Development of Chinese Martial Arts from the Perspective of Telling Good Chinese Stories
}

\author{
Li Li \\ Xi'an Jiaotong University City College, Xi’an Shanxi, China
}

Keywords: Telling good Chinese stories; Chinese martial arts; Development

\begin{abstract}
General Secretary Xi has proposed that telling Chinese stories should be regarded as the proposition for era development, and that telling good Chinese stories belongs to the mission of era development. In order to tell good Chinese stories, the Chinese voice should be spread through multiple channels. Thereinto, as an effective communication means, Chinese martial arts has gotten certain development under the background of "telling good Chinese stories". However, research showed that it is infeasible for Chinese martial arts to adopt western sports mode, and the compulsory integration of Chinese martial arts with western sports will lead to the loss of soul of Chinese martial arts. Based on this, this paper focuses on the research of the development process of Chinese martial arts from the perspective of "telling good Chinese stories".
\end{abstract}

\section{Introduction}

As the ranking of China in the world pattern has changed, and the acceleration of urbanization construction has resulted in cultural default, traditional culture needs to return. As the main embodiment of traditional culture, Chinese martial arts should also return. But in the return, enough attention must be paid to ontology awareness, the constraints of western sports mode should be broken, return of "traditional" must be pursued, the culture of martial arts must be focused on, and cultural confidence should be highlighted; in addition, Chinese characteristics should be embodied, good Chinese stories should be told. Beyond that, top-level design should be promoted and the road for China's development should be implemented.

\section{Modern deviation of Chinese martial arts}

\subsection{The germination of Chinese martial arts' deviation}

Since the failure in war not only collapsed the self-sufficient economic form in modern China, but also changed the social nature, China, a country always occupying a superior position in the world, lagged behind somewhat, western cultures began to attack the Chinese traditional culture based on Confucianism. Affected by western cultures, the development foundation of Chinese martial arts became weaker and weaker, and the martial arts itself has made innovations, striving to break the western constraints. However, there was no result. The development of Chinese martial arts was gradually transformed to the western sports mode. Under the constraints of "Western learning introduced into China", scholars, power-holders and martial arts experts reviewed Chinese martial arts again in succession from a new perspective, new reforms of Chinese martial arts were tried, and the development of Chinese martial arts ran counter to its belief. The main reason for this phenomenon is that the traditional thinking was impacted by advanced ideas of western countries, and the traditional thinking of Chinese martial arts was divorced from "the foundation". The main force driving such deviation came from the internal and external environment of Chinese society and the attraction to advanced cultures [1]. Based on this, Chinese martial arts has been gradually learning from western countries.

\subsection{Chinese martial arts always restricted by western sports mode}

After Chinese martial arts was included into the sports category, the western sports mode has 
exerted a comprehensive impact on it. For example, Ma Liang's "new martial arts" is the best example. The generation of "new martial arts" has made the development road of Chinese martial arts entirely adopt the western sports mode. The development of Chinese martial arts began to split, which was mainly due to the collision between western cultures and native culture as well as the combination between them. The reason also included that the development of Chinese martial arts gradually approached and imitated western countries. The collapse of Beiyang Government not only fundamentally shook the culture originally with strong sense of superiority, but also hindered the development of the culture, "utilization of west in Chinese form" was gradually transformed into "change the west into Chinese form".

Based on this, Chinese martial arts began to adopt the western sports mode to match with the western ideas and technology. The martial arts was improved according to the principles and methods of western countries. The "new martial arts" belongs to the symbolic products undergone improvement, which was gradually generalized and identified after generation. In order to conform to the western sports development requirements, Chinese martial arts kept innovating. Chinese martial arts also carried out innovation on sports and developed towards gymnastics, dances and vaudevilles to realize the "higher, faster, stronger" sports goal, however, the characteristics of martial arts itself were not reflected, and the definitions of "competitive sports" and "athletics martial arts" emerged in response to the needs of times. Athletics martial arts was divorced from the "parent" of original martial arts, although the gene of traditional martial arts was not abandoned, in order to meet the standards for competition, dissimilated gradually appeared, which gave martial arts a completely new outlook and cannot be entirely accepted by martial arts people .

\section{The return of Chinese martial arts}

\subsection{Strengthening the return of Chinese martial arts}

After the Opium War, the propagation process of western sport concepts in China was actually a process of positive contact and integration between western cultures and oriental culture. Due to the constraints of various factors, the western sport concepts always remained in the dominant position in the propagation, thus affecting the original ecology of Chinese martial arts. In this case, the western sports development mechanism was applied to Chinese martial arts compulsorily. However, it was difficult for western sports mode to integrate with Chinese martial arts, as they have their respective ideas and great disparity in terms of nature. Besides, since the western sports mode was applied to Chinese sports, the traditional culture, which had always occupied the dominant position, has declined, and Confucianism has been questioned by people. Given this, the western sports were compulsorily integrated into Chinese native culture, the promulgation scope of western sport concepts in the east became broader and broader, and the corresponding inherence of Chinese martial arts has changed. The development patterns of Chinese martial arts have been gradually replaced by those of western sports. The thought that guides the development road of Chinese martial arts has dissimilated, which made Chinese martial arts break away from the initial wind vane, and stride forward the road of learning from western countries. Thus it can be seen that return of the real should return to Chinese ideas and thoughts.

\subsection{The return of Chinese martial arts to highlight Chinese characteristics and tell good Chinese stories}

Like other products, Chinese martial arts should also be displayed, and its characteristics should be introduced. The presentation of exquisite traditional craftsmanship and unique historic culture of Chinese martial arts to the world is conducive to strengthening the international community's comprehensive understanding of the martial arts, and promoting the global society to more deeply understand the cultural thoughts of the martial arts, thus making martial arts more unique and orderly, break away from the western cultural concepts and return to its own characteristics, and ensuring the realization of outside-to-inside return of the development of Chinese martial arts. The 
breaking away is due to the loss of the developmental direction and the original features [2]. Therefore, the current return must improve the authenticity of Chinese martial arts, and without discount clarify the cause and effect of traditional fist kinds and the difference between schools. Besides, the return must firm the oriental cultural position, actively learn from the advantages of excellent cultures in different regions, and then promote Chinese martial arts to really walk into people's life. In order to tell good stories of Chinese martial arts, the means of conservation practices for Chinese martial arts must be innovated, and the difference between fist kind culture and fist kind technology cannot be broadened at will. Since the diversification of fist kind forms is not only the premise of telling good Chinese stories, but also the basis for spreading Chinese voice, fist kind is the main carrier for the inheritance of Chinese martial arts culture. However, because of unbalanced regional development, fist kind has had significant stratification, the cause of which is the lack of fist kind consciousness. Hence, in order to promote the development of Chinese martial arts from the perspective of telling good Chinese stories, fist kind consciousness must be improved, the characteristics of various fist kinds should be highlighted, and fist kind should continue to be carried forward.

\section{Conclusions}

In conclusion, the purpose of summing up the development history of Chinese martial arts is to review the historical period from an objective perspective. With the rapid development of China and the once again establishment of its national self-confidence, the return of Chinese martial arts will definitely develop in the east, as western culture did not play an effective role in the development of Chinese martial arts, and Chinese martial arts is the culture foundation of Chinese nation and has rich cultural atmosphere. Therefore, the national subject consciousness should be excavated from traditional culture, and the future development planning of Chinese martial arts should be reviewed.

\section{References}

[1] Tang Meiyan, Wang Gang. Difference comparison between Chinese martial arts and western sports from physical perspective [J]. Sports Science, 2014 (34): 82.

[2] Wang Gang, Zhang Dazhi. Moving from sports towards culture: the inevitable choice for contemporary development of Chinese martial arts [J]. Journal of Journal of Chengdu Sport University, 2013, (6): 3. 